\title{
Rancang Bangun Aplikasi Terapi Wicara Grow SCDC (Special Child Development Centre) Berbasis Android
}

\author{
Faizin Fifaridillah ${ }^{1)}$, Atiqah Meutia Hilda ${ }^{2) *}$ \\ ${ }^{1,2)}$ Universitas Muhammadiyah Prof. Dr. HAMKA, \\ Jl. Tanah Merdeka No. 6, Kp. Rambutan, Jakarta Timur \\ ${ }^{1)}$ Faizinfifaridillah92@gmail.com, \\ Corresponding author: atiqahmeutiahilda@uhamka.ac.id
}

\begin{abstract}
Abstrak - Klinik Tumbuh Kembang Anak Grow SCDC (Special Child Development Centre) merupakan salah satu pusat terapi untuk perkembangan kesehatan anak, dimana kegiatan yang ada di dalamnya terdapat beberapa fasilitas terapi untuk perkembangan anak yang mengalami gangguan kesehatan. Salah satu gangguan adalah berbahasa atau bicara. Aplikasi terapi wicara dibangun dengan berbasis android menggunakan metode Extreme Programming. Aplikasi terapi wicara menggunakan metode perubahan teks menjadi suara (text to speech) dan metode suara menjadi teks (speech to text). Metode text to speech dilakukan dengan menyebutan nama kartu berisi gambar dan nama kartu. Pada saat kartu dipilih, aplikasi akan menyebutkan nama dari kartu tersebut. Metode text to speech dilakukan dalam fitur game tebak kartu. Game tebak kartu berisi daftar dari kartu yang dapat ditebak menggunakan tombol voice, pada saat tombol voice ditekan, suara yang dikeluarkan user akan direkam dan selanjutnya rekaman suara akan diubah menjadi teks. Hasil teks akan dicocokan dengan nama dari kartu yang dipilih, teks akan di periksa apakah jawaban bernilai benar atau salah. Aplikasi terapa wicara ini dirancang dan dibuat dengan beberapa bahasa pemrograman, yaitu Dart, PHP (Perl Hypertext Preprocessor), framework Flutter dan paket pendukung yaitu Cloud Speech API untuk penerapan metode text to speech dan speech to text. Sistem manajemen basis data menggunakan piranti lunak MySQL. Dapat disimpulkan pada penelitian ini fitur dan fungsi yang ada didalam aplikasi sudah sesuai dengan keinginan responden dikarenakan memiliki nilai rata-rata kuesioner yaitu 87\%, dengan pernyataan aplikasi terapi wicara ini sudah stabil dan lancar bagi responden.
\end{abstract}

Kata kunci: Terapi Wicara, Kartu, speech to text, text to speech, Android.

\begin{abstract}
The Grow SCDC (Special Child Development Center) is one of the therapy centers for children's health development, where the activities include several therapy facilities for the development of children with health problems. One of the distractions is language or speech. Speech therapy application is built based on android using the Extreme Programming method. The speech therapy application uses the text to speech method and the speech to text method. The text to speech method is done by saying the name of the card containing the picture and the name of the card. When a card is selected, the application will say the name of the card. The text to speech method is carried out in the guess card game feature. The card guessing game contains a list of cards that can be guessed using the voice button, when the voice button is pressed, the voice issued by the user will be recorded and then the voice recording will be converted into text. The text results will be matched with the name of the selected card, the text will be checked whether the answer is true or false. This speech therapy application is designed and made with several programming languages, namely Dart, PHP (Perl Hypertext Preprocessor), the Flutter framework and a supporting package namely the Cloud Speech API for implementing the text to speech and speech to text methods. Meanwhile, the database management system uses MySQL software. It can be concluded in this study features and functions in the application are in accordance with the wishes of the respondents because it has an average questionnaire value of $87 \%$, with a statement that the speech therapy application is stable and smooth for respondents.
\end{abstract}

Keyword: Speech Therapy, Card, speech to text, text to speech, Android. 


\section{PENDAHULUAN}

\section{A. Latar Belakang}

Setiap orang tua akan selalu memperhatikan pertumbuhan anaknya, salah satu kondisi yang mungkin ditakuti orang tua mengenai tumbuh kembang anak adalah adanya keterlambatan bicara. Umumnya pertumbuhan anak yang berusia 1,5 tahun paling tidak sudah dapat mengucapkan 1 sampai 5 kata. Seorang anak dikatakan mengalami gangguan keterlambatan bicara pada saat berumur 2 sampai 3 tahun dalam perkembangannya. Gangguan bicara dapat dideteksi sejak masih kanak-kanak, dan jenis gangguan bicara dapat dibagi ke beberapa jenis gangguan, diantaranya spektrum autisme, atraksia, disleksia, gagap, keterlambatan berbicara (speech delay) dan cerebral palsy.[1]

Adanya gangguan gejala bicara pada usia dini harus segera ditangani dengan cara yang tepat. Klinik Tumbuh Kembang Anak Grow SCDC (Special Child Development Centre) dalam kegiatan terapisnya masih menggunakan cara manual. Untuk memudahkan staff klinik maka akan dibuatkan sebuah aplikasi terapi wicara yang dapat digunakan staff klinik dalam membantu kegiatan terapisnya.

Aplikasi terapi wicara mempunyai beberapa fitur, yaitu fitur memilih gambar di dalam kartu yang akan menghasilkan suara sesuai gambar yang dipilih dan menu menyebutkan nama sesuai kartu yang dipilih. Pada fitur pilih kartu, anak diharapkan dapat mendengar dengan baik Bahasa Indonesia yang baik dan benar dalam mengenal nama-nama gambar yang terdapat di kartu, pada fitur ini metode yang digunakan adalah metode Text To Speech, Text To Speech adalah metode perubahan sebuah teks menjadi suara, sedangkan pada fitur game tebak kartu anak diharapkan dapat menyebutkan nama-nama gambar yang terdapat di kartu dan suara yang dihasilkan anak akan diubah menjadi teks, yang selanjutnya akan di periksa apakah anak mengucapkan nama-nama tersebut dengan benar atau tidak dan pada fitur ini metode yang digunakan adalah metode Speech To Text, Speech To Text adalah metode perubahan sebuah suara menjadi teks.

Di dalam aplikasi juga terdapat fitur membuat kartu sendiri atau custom kartu, fitur ini digunakan untuk user membuat kartu sendiri dengan gambar dan nama kartu sesuai yang diinginkan. Pengambilan data dlakukan dengan cara kuesioner kepada staff Klinik Tumbuh Kembang Anak Grow SCDC (special child development centre) mengenai permasalahan yang ada, hasil kuesioner mendapatkan hasil $88 \%$. Berdasarkan hal tersebut dilakukan penelitian dengan judul "Rancang Bangun Aplikasi Terapi Wicara Klinik Tumbuh Kembang Anak Grow SCDC (Special Child Development Centre) Berbasis Android".

\section{B. Rumusan Masalah}

Berdasarkan pada latar belakang yang telah penulis jelaskan, maka dapat disimpulkan perumusan masalah sebagai berikut:

1. Bagaimana merancang suatu aplikasi terapi wicara dengan metode text to speech (TTS) dan speech to text (STT) yang diharapkan dapat membantu anak untuk dapat berbicara dengan baik dan benar berbasis android?

2. Bagaimana membuat suatu aplikasi yang dapat digunakan para terapis klinik tumbuh kembang anak untuk terapi kepada anak yang mengalami gangguan berbicara?

\section{Batasan Masalah}

Mengingat banyaknya perkembangan yang bisa ditemukan dari masalah ini, maka perlu adanya batasan-batasan masalah agar lebih terarah dan mencapai target yang diinginkan, berikut adalah batasan masalah:

1. Metode yang digunakan pada menu pilih gambar pada kartu adalah text to speech (TTS).

2. Metode yang digunakan untuk menangkap suara menggunakan metode speech to text (STT).

3. Aplikasi terapi wicara ini untuk membantu anak yang mengalami gangguan bicara.

4. Aplikasi terdiri dari beberapa gambar yang ada didalam kartu.

5. Kartu dikategorikan kedalam beberapa kategori, yaitu kategori alat mandi, buah, hewan, kata kerja, anggota tubuh, makanan dan minuman.

\section{Tujuan Penelitian}

Adapun Tujuan dari penelitian ini adalah:

1. Membuat perangkat lunak untuk bisa digunakan kepada anak yang mengalami gangguan berbicara.

2. Mengimplementasikan aplikasi yang dapat digunakan terapis klinik tumbuh kembang anak agar dapat dijadikan alat terapi bicara.

3. Melakukan rancangan aplikasi yang mudah digunakan oleh terapis klinik tumbuh kembang anak.

\section{E. Manfaat Penelitian}

Beberapa manfaat penelitian yang dapat diambil adalah: 
1. Dapat membantu orang tua dalam mengembangkan daya ucap anak yang mengalami gangguan bicara.

2. Dapat dijadikan media terapi pada anak yang mengalami gangguan bicara di klinik tumbuh kembang

\section{LANDASAN TEORI}

\section{A. Kerangka Teori}

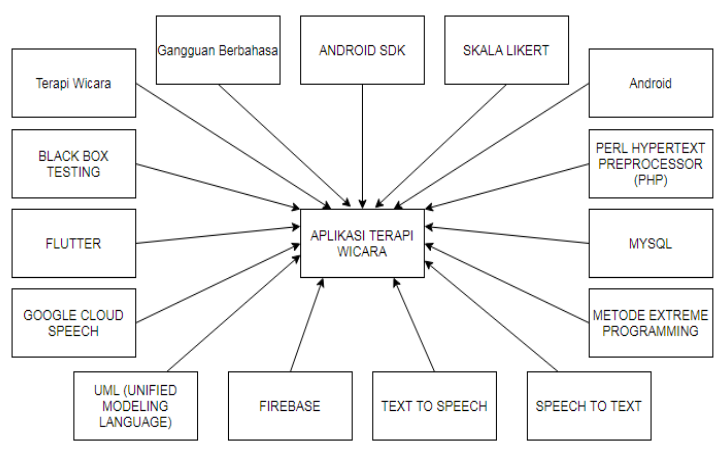

Gambar 2-1 Kerangka teori

\section{B. Terapi Wicara}

Latihan dengan cara perbaikan kebiasaan berbicara disebut juga dengan terapi wicara. Manfaat terapi wicara antara lain mempermudah seorang anak yang mengalami gejala berbicara. Adapun manfaat lainnya, seorang anak dapat menguasai ucapan dengan baik. Terapi wicara didasari oleh fonem yang terbentuk, ucapan dasar dan kesalahan ucapan yang mungkin terjadi. [2]

\section{Metode Extreme Programming}

Extreme Programming merupakan metodologi pengembangan sebuah perangkat lunak dan juga suatu bagian dari agile software development methodologies yang lebih berfokus kepada coding untuk aktivitas utama pada siklus pengembangan. [3]

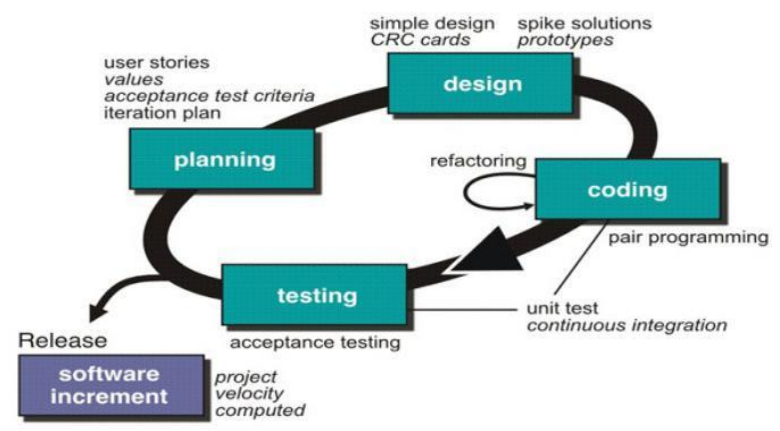

Gambar 2-2 Metode extreme programming Copyright $\odot 2020$ FT-UHAMKA. - All rights reserved DOI:10.22236/teknoka.v5i.313

\section{Text To Speech}

Sebuah sinyal ucapan yang secara otomatis mentranskripsi teks ke fonem pada kalimat adalah sebuah sistem yang bernama Text To Speech (TTS).

Istilah linguistik adalah satuan terkecil pada sebuah bahasa yang dimana bisa menampilkan makna yang berbeda. Suatu konverter teks ke sebuah fonem bertugas untuk mengubah teks kedalam bahasa, sehingga sebuah teks dapat berubah menjadi rangkaian suatu kode bunyi yang dapat direpresentasikan kedalam kode fonem. [4]

\section{E. Speech To Text}

Teknologi Speech Recognition sudah sangat berkembang untuk saat ini. Suara yang dikeluarkan oleh seseorang, memiliki struktur yang begitu kompleks, misal, untuk satu kata yang dikeluarkan dari beberapa orang dapat mempunyail hasil struktur suara yang juga berbeda, akan tetapi sistem harus diwajibkan dapat memahami sebagai kata yang dapat dikatakan sama. Adapun sebab-sebab yang dapat mempengaruhi suara yang dihasilkan antara lain umut, kesehatan, jenis kelamin dan juga psikologi seseorang.

Dengan adanya Speech To Text sebuah perangkat dapat memahami dan mengenali suatu kata atau kalimat yang dikeluarkan dari seseorang dengan metode digitalisasi dan menyamakan suatu sinyal dalam berbentuk digital dengan pola yang ada dan disimpan didalam sebuah perangkat. Kalimat atau kata yang dihasilkan, bentuknya akan diubah kedalam sinyal dengan mengubah sebuah gelombang menjadi angka yang terkumpul, dan disesuaikan dengan sebuah kode untuk dapat mengenali kalimat atau kata tersebut. [5].

\section{F. Flutter}

Flutter adalah sebuah SDK atau framework open source yang dikembangkan oleh Google untuk membuat atau mengembangkan aplikasi yang dapat berjalan dalam sistem operasi Android dan iOS. Flutter menggunakan bahasa pemrograman Dart dalam pengkodean. Perbedaan framework Flutter dengan yang lainnya yaitu dalam build aplikasi, pada framework ini semua kodenya di compile dalam kode native-nya (Android NDK, LLVM, AOTcompiled) tanpa ada interpreter pada prosesnya sehingga proses compile-nya menjadi lebih cepat.[6]

\section{G. Cloud Speech API}

Perusahaan terkemuka Google menciptakan suatu kerangka kerja yang dimana sistem dapat mengenali sebuah suara dan suara tersebut diubah menjadi sebuah teks atau string dan dikemudian dimasukkan ke 
mesin pencarian Google dan menampilkan hasil pencarian sesuai teks yang dimasukkan. Google Speech atau biasa juga disebut Speech Recognition adalah sebuah API yang telah disediakan Google agar dapat mengenali suara dengan cara digitalisasi sebuah kata. Sedangkan pengenalan sebuah kalimat atau kata dengan menggunakan suara yang dikeluarkan manusia yang dimasukkan, lalu dibaca dengan komputer. Speech Recognition adalah sebuah teknologi perkembangan komunikasi komputer dengan manusia agar dapat meminimalisasi penggunaan perangkat keras atau hardware seperti mouse, keyboard dan juga yang lainnya. [7]

\section{H. Perl Hypertext Preprocessor (PHP)}

PHP singkatan dari Hypertext Preprocessor yang digunakan sebagai bahasa script serverside dalam pengembangan Web yang disisipkan pada dokumen HTML. (Kasiman Peranginangin, 2006, dalam jurnal dani dkk, Indonesian Jurnal on Networking and Security (IJNS) Hal-15 Volume 2 No 3 - Juli 2013ISSN: 2302-5700).[8]

\section{MySQL}

MySQL adalah suatu perangkat lunak database relasi atau Relational Database Management System (RDBMS) yang didistribusikan gratis di bawah lisensi GPL (General Public License). Dimana setiap orang bebas menggunakan MySQL, namun tidak boleh dijadikan produk turunan yang dijadikan closed source atau komersial. (Abdul Kadir, 2002 dalam jurnal Nur, Seminar Riset Unggulan Nasional Informatika dan Komputer FTI UNSA Seminar Riset Unggulan Nasional Informatika dan Komputer FTI UNSA 2013 Hal-114 Vol 2 No.1-Maret-2013ISSN:2302-1136).[8]

\section{J. Unified Modeling Language (UML)}

UML (Unified Modeling Language) adalah bahasa pemodelan untuk sistem atau perangkat lunak yang berparadigma 'berorientasi objek.[9]

Tujuan dari penggunaan UML (unified Modeling Language), antara lain:

1. Dapat memberikan bahasa permodelan visual kepada pengguna dari berbagai macam pemerograman maupun proses rekayasa.

2. Dapat menyatukan praktek-praktek terbaik yang ada dalam permodelan.

Dapat memberikan model yang siap untuk digunakan, merupakan bahasa permodelan visual yang ekspresif untuk mengembangkan sistem dan untuk saling menukar model secara mudah.
1. Dapat berguna sebagai blue print, sebab sangat lengkap dan detail dalam perancangannya yang nantinya akan diketahui informasi yang detail mengenai koding suatu program.

2. Dapat memodelkan sistem yang berkonsep berorientasi objek, jadi tidak hanya digunakan untuk memodelkan perangkat lunak (softwere) saja.

3. Dapat menciptakan suatu bahasa permodelan yang nantinya dapat dipergunakan oleh manusia maupun oleh mesin.

\section{a. Use Case Diagram}

Use case diagram yaitu salah satu jenis diagram pada UML yang menggambarkan interaksi antara sistem dan aktor, use case diagram juga dapat mendeskripsikan tipe interaksi antara pengguna sistem dengan sistemnya. Sedangkan use case diagram memfasilitasi komunikasi diantara analis dan pengguna serta antara analis dan client.

\section{b. Diagram Activity}

Sebuag diagram yang menampilkan alur atau langkah didalam proses kerja, sebuah titik pengambilan keputusan, beberpa aktor yang menjalankan aktivitas dan beberapa objek dalam alur kerja.

\section{c. Class Diagram}

Suatu diagram pada UML yang dapat menampilkan beberapa kelas, paket ataupun relasi-relasi yang ada pada sebuah sistem merupakan diagram yang bernama Class Diagram.[10]

\section{d. Deployment Diagram}

Deployment diagram berfungsi sebagai hubungan antara komponen hardware atau perangkat keras dalam infrastruktur sistem informasi yang dimiliki. Contoh, pada saat merancang sebuah sistem informasi dengan menggunakan sebuah jaringan yang sangat luas, diagram ini dapat berfungsi untuk menampilkan komunikasi hubungan antara node-node yang berbeda dalam suatu jaringan.[10]

\section{METODOLOGI PENELITIAN}

Dalam penelitian ini penulis menggunakan metode extreme programming. Pada extreme programming metode lebih berfokus pada coding (pengkodean) untuk aktivitas utama pada siklus pengembangan untuk bisa lebih responsif terhadap kebutuhan klien. 


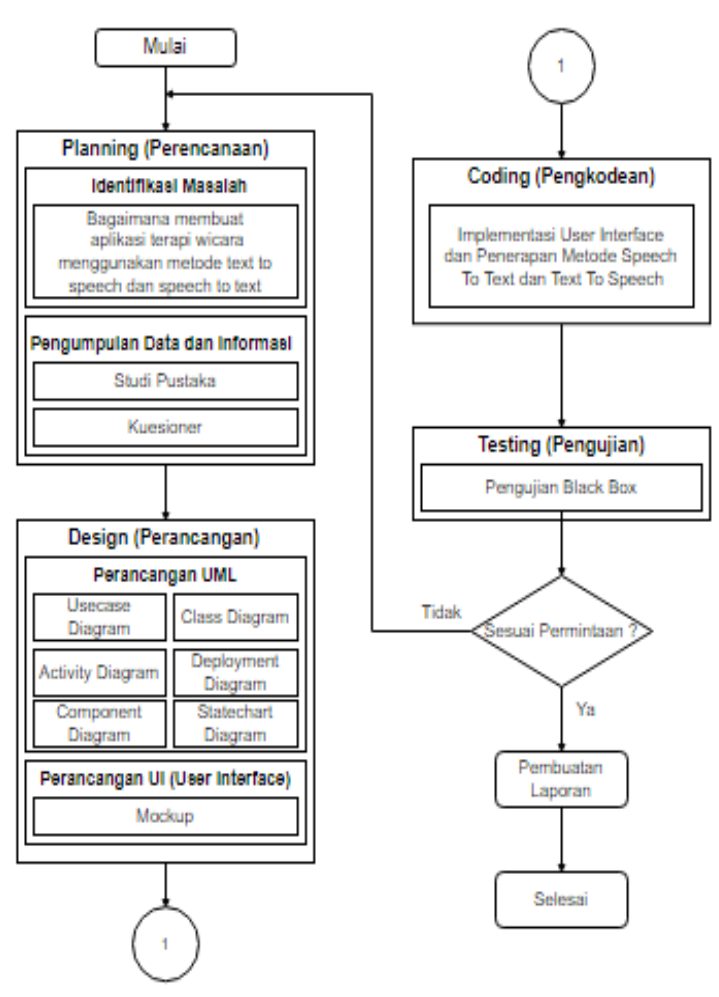

Gambar 3-1 Metodologi penelitian.

\section{HASIL DAN PEMBAHASAN}

\section{A. PERANCANGAN SISTEM}

Tahap ini peneliti menentukan kebutuhan sistem yang meliputi perangkat keras dan perangkat lunak yang diperlukan untuk mendukung berhasilnya proses pembuatan aplikasi ini. Kebutuhan perangkat sistem meliputi hal-hal berikut:

\section{a. Perangkat Keras (Hardware)}

Perangkat keras yang digunakan untuk membuat sistem ini adalah sebuah laptop dengan spesifikasi :

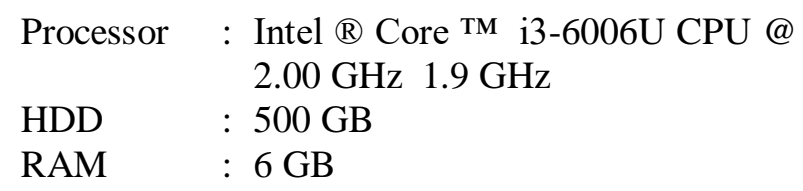

\section{b. Perangkat Lunak (Software)}

Untuk membantu sistem ini dibutuhkan software yang dapat membantu membuat penulisan source code dan desain template. Dalam hal ini software yang digunakan adalah :

Sistem Operasi : Kali Linux

Bahasa Pemrogramman: Dart, PHP, Flutter

$\begin{array}{ll}\text { Text Editor } & : \text { Visual Studio Code } \\ \text { DBMS } & : \text { MySQL }\end{array}$

\section{c. Perangkat Android}

Perangkat Android yang digunakan untuk melakukan pengujian dan digunakan untuk user adalah :

OS (minimal) : Android 7.0 (Nougat)

\section{d. Rancangan Use Case Diagram}

Perancangan sebuah use case diagram digunakan untuk menjelaskan interaksi dan kegiatan antara pengguna/aktor dan sistem pada aplikasi. Use case diagram untuk aplikasi terapi wicara ini terdiri dari 2 (dua) aktor yaitu admin dan user, yang dimana aktor dapat mengelola data yang ada pada aplikasi. Admin mengelola data kartu dan data game kartu yang nantinya dapat ditampilkan pada aplikasi android terapi wicara dan admin juga dapat mengelola data user admin yang terdaftar. Aktor user dapat memilih kategori kartu, memilih kartu dari list kategori kartu, menekan tombol play kartu, menekan tombol hapus kartu, memilih menu game tebak kartu, memilih kategori game kartu, mengisi nama untuk game tebak kartu, menebak kartu pada game tebak kartu, memilih menu custom kartu, membuat custom kartu sendiri dan menghapus custom kartu.

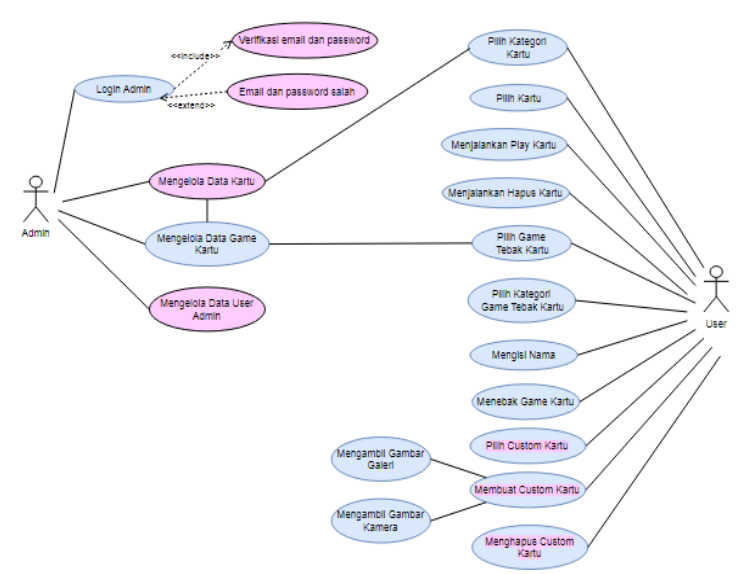

Gambar 4-1 Use case diagram.

\section{e. Rancangan Class Diagram}

Penggambaran sebuah struktur dan sebuah kelas sering disebut dengan class diagram. Class diagram merupakan bagian UML view yaitu dimana didalam class diagram dapat menjelaskan fungsional sistem aplikasi secara struktur dan object yang dinamis untuk dapat mengirim pesan kepada object yang lain. 


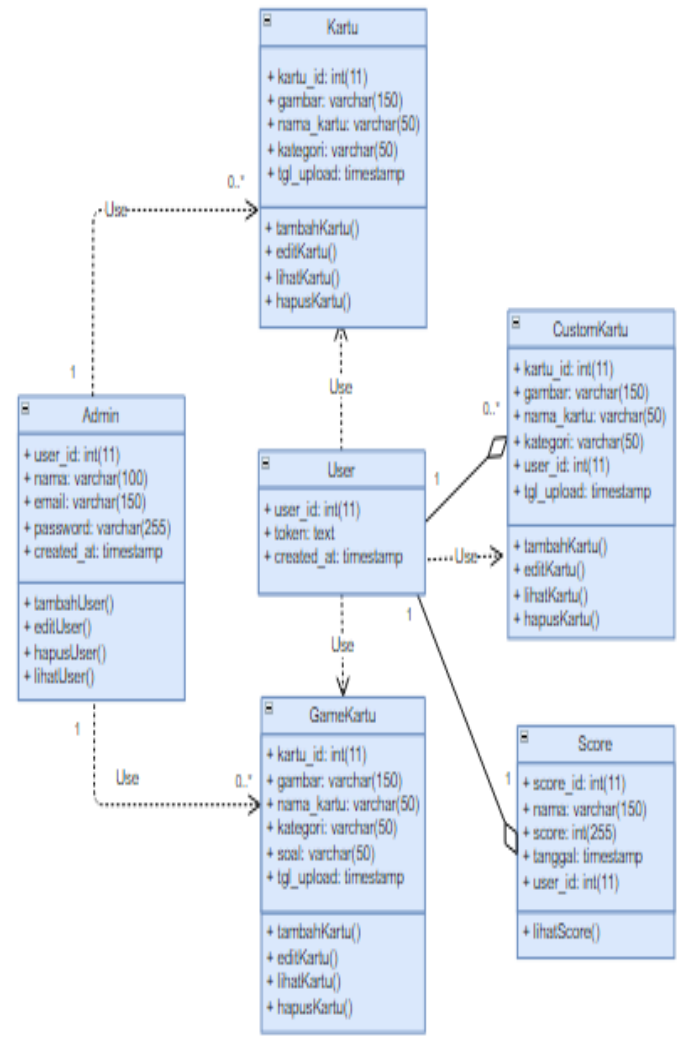

Gambar 4-2 Class diagram

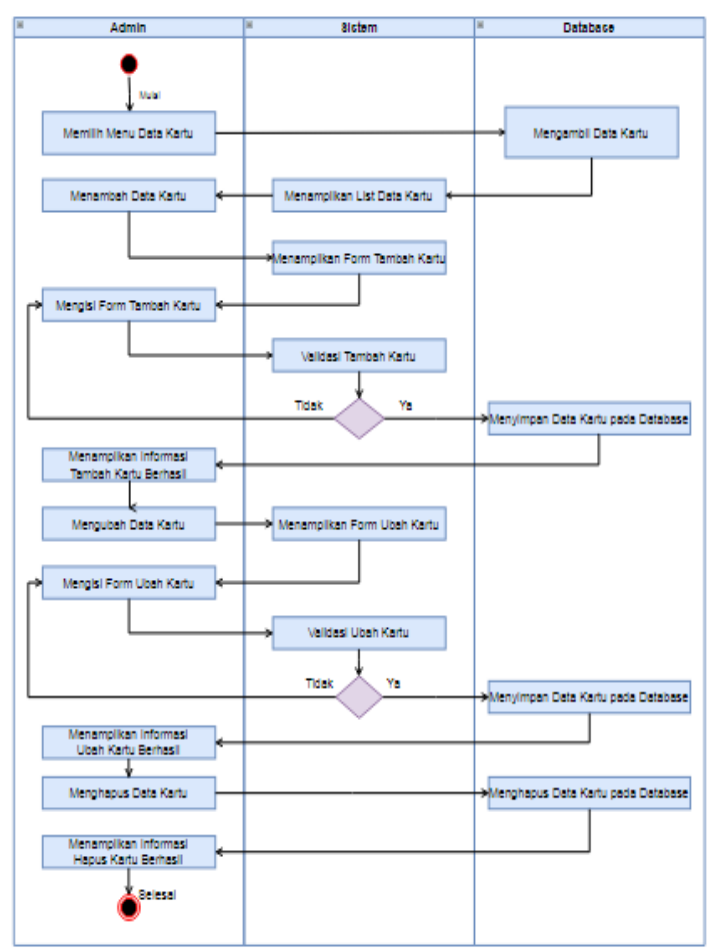

Gambar 4.3 Activity mengelola data kartu

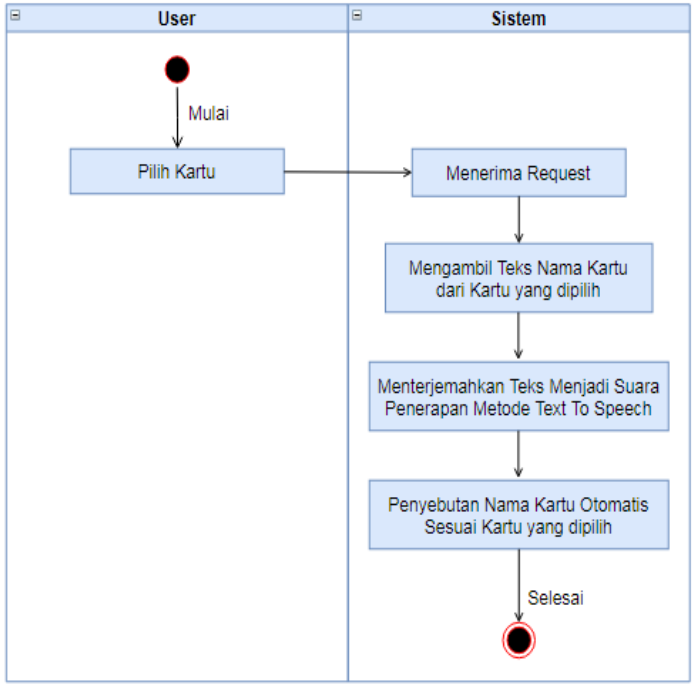

Gambar 4-4 Activity pilih kartu

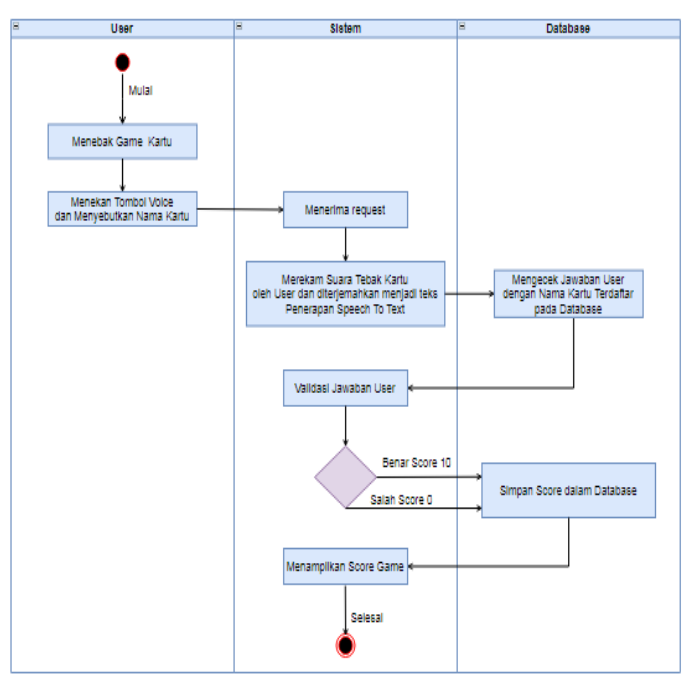

Gambar 4-5 Activity menebak game kartu

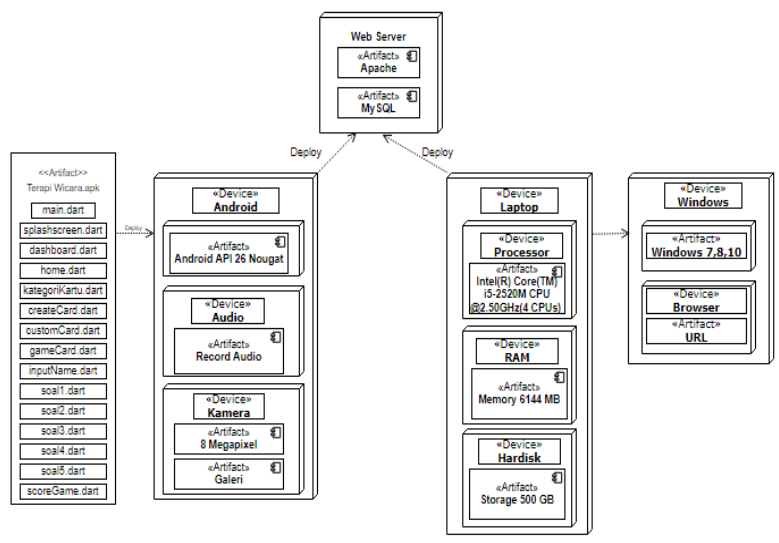

Gambar 4-6 Deployment diagram 


\section{B. IMPLEMENTASI DAN PENGUJIAN}

\section{a. Halaman Login Web Aplikasi}

Halaman ini adalah tampilan login pada web aplikasi. Dimana admin dapat melakukan proses login dan dapat masuk ke dashboard admin untuk dapat mengelola data-data yang ada.

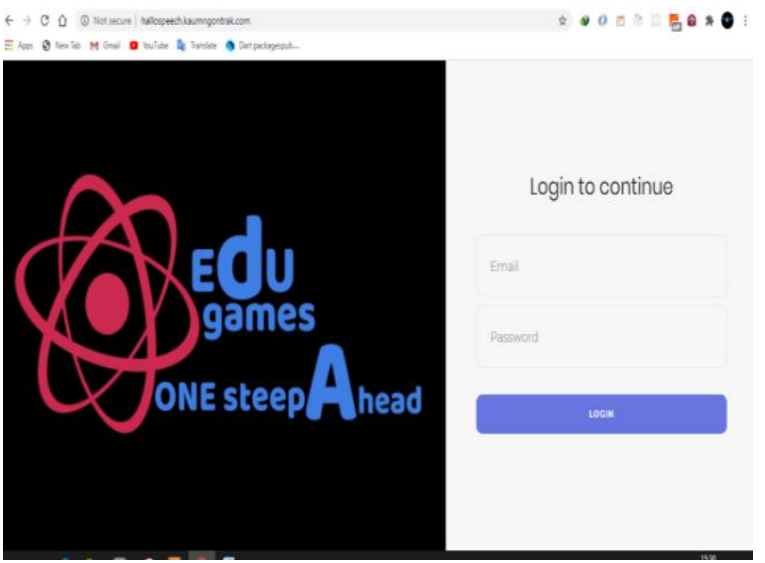

Gambar 4-7 Login web aplikasi

\section{b. Halaman Dashboard Web Aplikasi}

Sesudah login dan memasukkan email dan password dengan benar, admin akan diarahkan kedalam halaman dashboard.

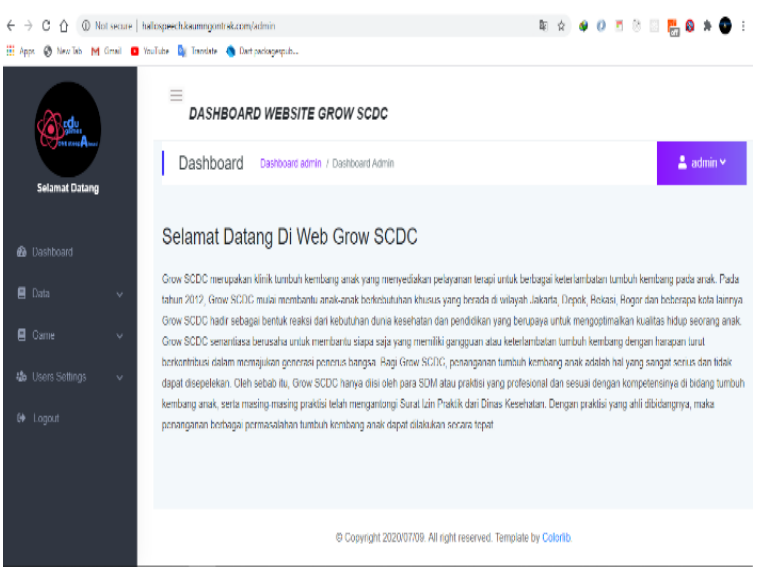

Gambar 4-8 Dashboard web aplikasi

\section{c. Halaman Home Android}

Tampilan ini merupakan halaman home aplikasi android terapi wicara, halaman ini berisikan semua keseluruhan fitur-fitur yang ada pada aplikasi. Pada halaman ini juga terdapat beberapa kartu yang dapat digunakan user untuk melakukan terapi wicara dengan cara memilih kartu yang ada, dan kemudian kartu yang dipilih akan mengeluarkan suara sesuai nama kartu yang dipilh.

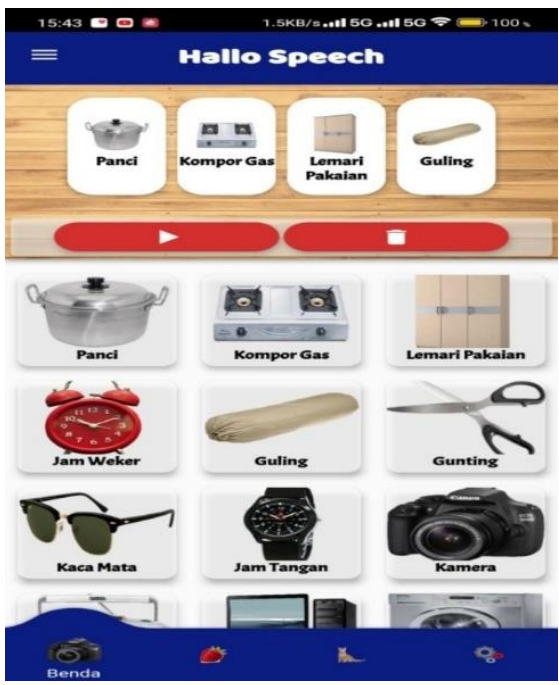

Gambar 4-9 Home android

\section{d. Halaman Membuat Custom Kartu}

Tampilan ini adalah halaman membuat custom kartu, halaman ini digunakan user ketika ingin membuat kartu sendiri yang nantinya akan ditampilkan pada kategori custom kartu, dan dapat juga mengeluarkan suara dari nama kartu yang telah user buat.

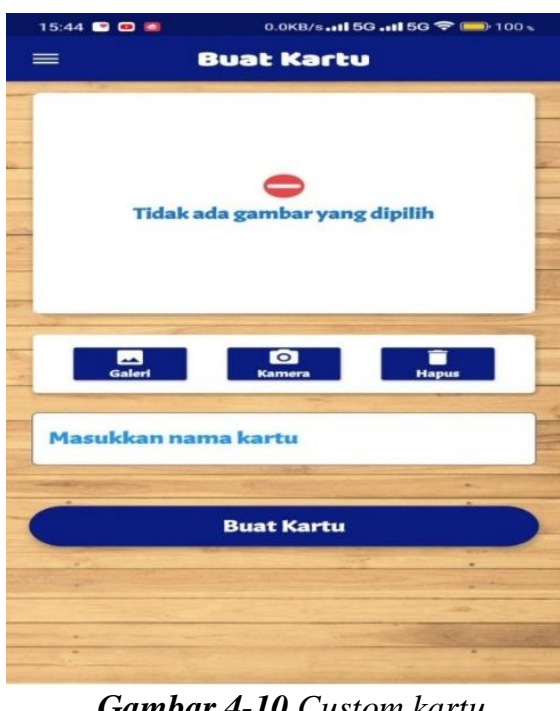

\section{e. Halaman Game Tebak Kartu}

Tampilan ini adalah halaman tebak kartu ketika user telah menebak nama dari kartu yang ada dengan mengeluarkan suara, suara yang dikeluarkan user kemudian akan diterjemahkan ke dalam teks, dan kemudian hasil dari teks akan di cek sistem, apakah jawaban tebak kartu yang dilakukan user benar atau salah, jika benar user akan mendapatkan score bernilai 10, jika salah user tidak akan mendapatkan nilai. 


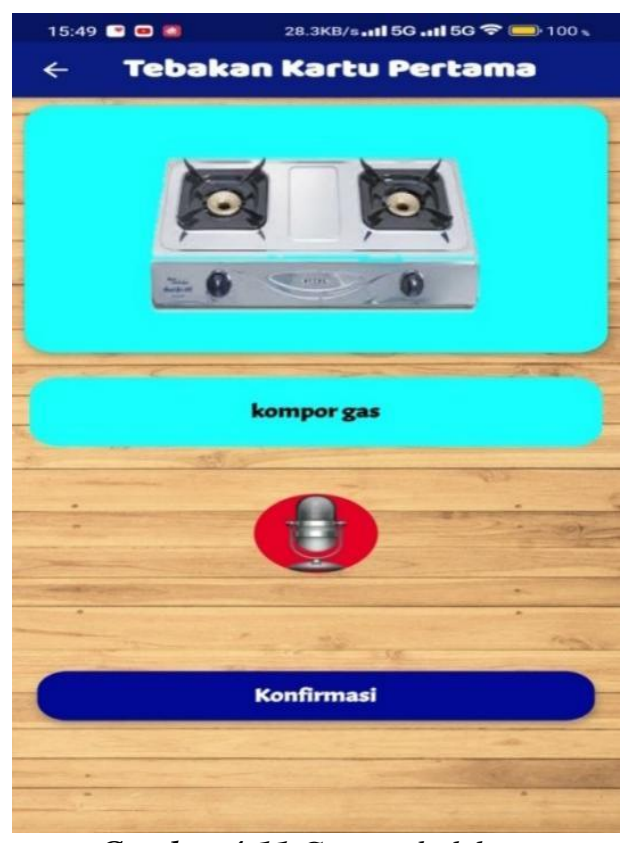

Gambar 4-11 Game tebak kartu

\section{f. Halaman Popup Jawaban Benar}

Tampilan ini adalah halaman sebuah popup pada aplikasi jika jawaban pada game tebak kartu bernilai benar.

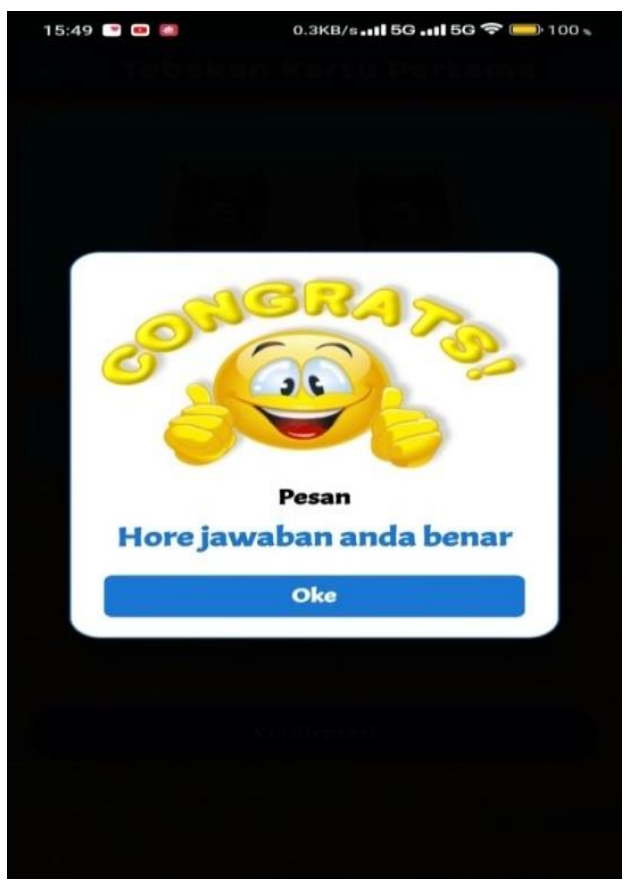

Gambar 4-12 Popup jawaban benar

\section{g. Halaman Popup Jawaban Salah}

Tampilan ini adalah halaman sebuah popup pada aplikasi jika jawaban pada game tebak kartu bernilai salah.

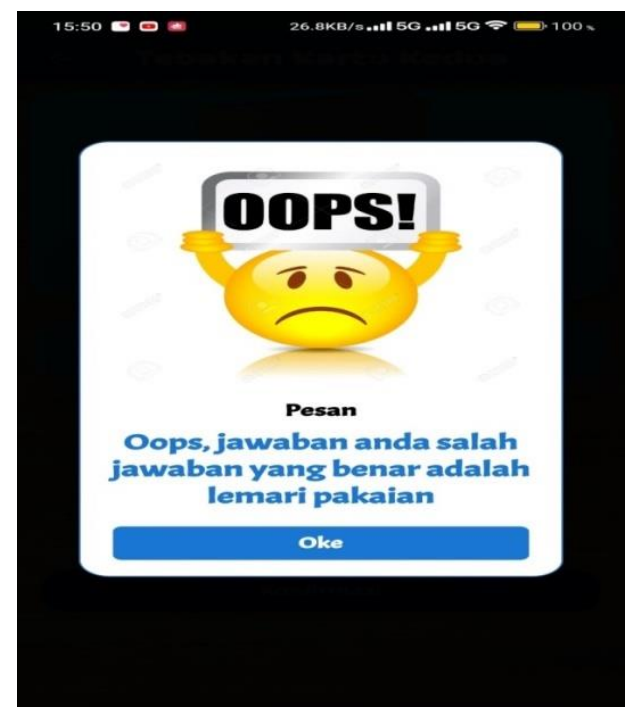

Gambar 4-13 Popup jawaban salah

\section{h. Halaman Score Game Tebak Kartu}

Tampilan ini adalah halaman hasil score game tebak kartu, dimana halaman ini berisikan sebuah score game dari beberapa user yang telah mengikuti game tebak kartu.

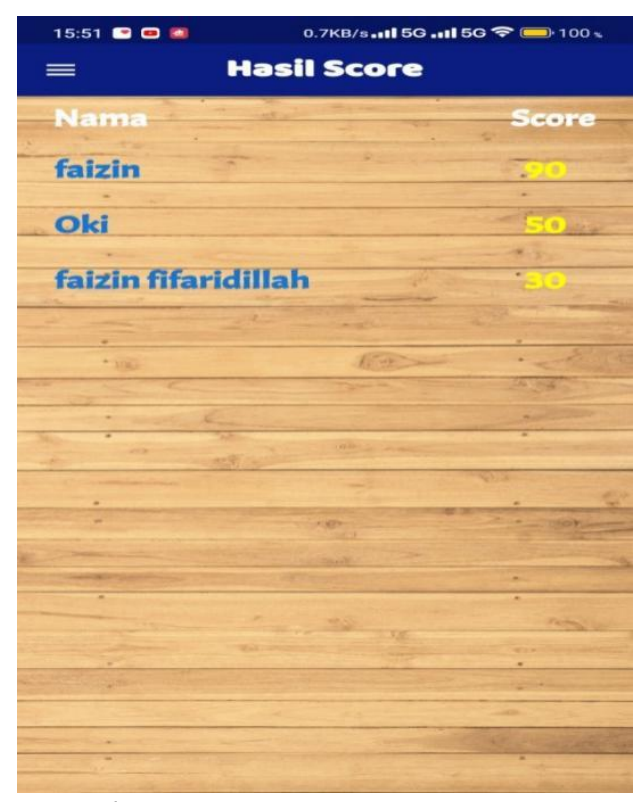

Gambar 4-14 Score game tebak kartu

\section{SIMPULAN}

Hasil atau kesimpulan penelitian dengan judul "Rancang Bangun Aplikasi Terapi Wicara Klinik Tumbuh Kembang Anak Grow SCDC (Special Child 
Development Centre) Berbasis Android" adalah sebagai berikut:

1. Tercapainya pembuatan aplikasi terapi wicara untuk Klinik Tumbuh Kembang Anak Grow SCDC (Special Child Development Centre) Berbasis Android. Dari hasil kuesioner uji aplikasi dengan 20 responden staff klinik tumbuh kembang anak dengan presentase rata-rata $87 \%$, dapat disimpulkan bahwa aplikasi terapi wicara sudah dapat dijalankan dengan sangat baik.

2. Dari hasil kuesioner uji coba aplikasi, didapatkan nilai dengan persentase rata-rata $87 \%$. Dengan didapatkannya nilai tersebut dapat dinyatakan aplikasi terapi wicara ini baik digunakan untuk membantu proses terapi wicara di Klinik Tumbuh Kembang Anak Grow SCDC (Special Child Development Centre).

3. Tercapainya aplikasi yang user friendly, pada aplikasi terdapat beberapa fitur yang sudah secara jelas dirancang untuk mudah digunakan dalam pengoperasiannya, seperti fitur pilih kartu, user hanya perlu memilih kartu dan sistem menyebutkan nama kartu dari kartu yang dipilih, dan fitur game tebak kartu, user hanya perlu menyebutkan nama kartu yang tersedia dan sistem menilai jawaban dari user. Dan adapun hasil data skala likert pada pertanyaan 1, presentase yang didapatkan mencapai 100\%. Dari hasil tersebut dapat disimpulkan aplikasi ini sangat mudah digunakan oleh staff terapi klinik tumbuh kembang anak.

\section{KEPUSTAKAAN}

[1] K. Pengantar, Gangguan Berbahasa, vol. 15, no. 1.2015.

[2] L. Bicara, U. Tahun, and L. Vygotsky, “'HELPER' Jurnal Bimbingan dan Konseling FKIP UNIPA," vol. 35 , no. 1, pp. 19-30, 2018.

[3] T. Gumelar, R. Astuti, and A. T. Sunarni, "Sistem Penjualan Online Dengan Metode Extreme Programming," vol. 9, no. 2, pp. 8790, 2017.
[4] J. Dirmansyah, "Berbahasa Indonesia Berbasis Text To Speech Dan Speech Recognition Pada Perangkat Android," Semin. Teknol. Inf. dan Komun., vol. 1, no. x, pp. 18, 2015.

[5] E. Widiyanto, S. N. Endah, and S. Adhy, "Aplikasi Speech To Text Berbahasa Indonesia Menggunakan Mel Frequency Cepstral Coefficients Dan Hidden Markov Model ( Hmm )," Pros. Semin. Nas. Ilmu Komput. Undip, pp. 39-44, 2014.

[6] F. Enggar Krisnada and R. Tanone, "Aplikasi Penjualan Tiket Kelas Pelatihan Berbasis Mobile menggunakan Flutter," J. Tek. Inform. dan Sist. Inf., vol. 5, no. 3, pp. 281-295, 2020, doi: 10.28932/jutisi.v5i3.1865.

[7] A. Akbar et al., "IMPLEMENTASI GOOGLE SPEECH API PADA APLIKASI KOREKSI HAFALAN AL-QUR' AN BERBASIS ANDROID ( The Implementation of the Google Speech on Qur ' an Recitation Correction," vol. 1, no. 1, pp. 1-8, 2019.

[8] M. Muslihudin and A. Larasat, "Perancangan Sistem Aplikasi Penerimaan Mahasiswa Baru Di Stmik Pringsewu Menggunakan Php Dan Mysql," J. TAM, vol. 3, no. 2, pp. 1-8, 2016, doi: 10.1017/CBO9781107415324.004.

[9] D. Sukrianto and S. Agustina, "Pemanfaatan Sms Gateway Pada Sistem Informasi Absensi Siswa Di Sman 12 Pekanbaru Berbasis Web.," J. Intra Tech, vol. 2, no. 2, pp. 78-90, 2018, [Online]. Available: http://www.journal.amikmahaputra.ac.id/inde x.php/JIT/article/view/31.

[10] S. Pohan, "Pemodelan Uml Untuk Menentukan Kelulusan Penerimaan Siswa Baru Berbasis Web," J. Inform., vol. 3, no. 2, pp. 41-51, 2019, doi: 10.36987/informatika.v3i2.214. 